\title{
Passion vs. the Iron Cage: United States and European Evaluative Cultures
}

\author{
Juan Díez Medrano \\ Universidad Carlos III de Madrid \\ jdiez@ibei.org
}

I read Lamont's book How Professors Think soon after its release in 2009. After seven years in Europe (two in Germany and five in Spain), back from an eighteen-year academic career in the United States, I had often reflected on the contrasts between the academic systems in the United States and Europe, and on the distorted image that the European public has of the former. Lamont's book provided me with an opportunity to check on my assumptions about the U.S. system and with an authoritative account of this system that I could pass on to my European colleagues. The book is of course much more than this: a brilliant analytical and empirical contribution to the comparative study of evaluative cultures, a topic to which the author has devoted much of her career and intellectual effort (i.e. Money, Morals, and Manners, 1992; The Dignity of Working Men, 2002). The book is written in a style that satisfies both the public-minded citizen and the dedicated scholar. This is because Lamont has cleverly pushed most of the conversation and intellectual debate with social scientists to footnotes. In fact, reading these footnotes is as enriching and engaging as reading the main text; they walk the reader through some of the most interesting contemporary discussions in the sociology of culture, economic sociology, and the sociology of science.

How Professors Think relies on in-depth interviews and Lamont's own experience to provide an account of how the humanities and the social sciences in the United States conceive of research excellence and how interdisciplinary panels in fellowship competitions reach their decisions. The author shows that decisions result from the combined impact of organizational constraints (e.g. materials subject to consideration, criteria emphasized, time constraints, sequencing of evaluations), the formal and informal criteria of evaluation upon which panelists rely (e.g. originality, significance), and the interactional 
dynamics in panels. Lamont systematically examines the role played by all of these factors but privileges the analysis of the interactional dynamics and the diversity of criteria of excellence. Regarding the former, she emphasizes the roles played by panelists' genuine commitment to reward the best proposals, their relative authority (e.g. reputation, institutions, personality), and their strategic games (e.g. alliances, horse-trading). Regarding the latter she stresses that research proposals shine differently under different lights and due to contrasts across disciplines in conceptions of excellence and the weight assigned to different criteria.

Against the Mertonian tradition, Lamont concludes that academic excellence is not an objective quality waiting to be discovered through honest and systematic application of universalistic evaluative criteria. There are too many legitimate criteria of excellence for that. Against the Bourdieusian tradition, she argues that evaluators are not mere self-interested strategists in an academic field. Evaluators' self-concept as scholars-their genuine interest in the pursuit of knowledge-is most often than not their overriding concern when ranking research proposals and debating their relative merits with other panelists. One ends the book with the feeling that panelists in the elite competitions that Lamont studied take their task very seriously, find participation in granting committees extremely rewarding from an intellectual point of view, and attach great legitimacy to the way the selection system works. I especially like chapter four, on the pragmatics of project selection in fellowship competitions. In it, Lamont stresses the significance of collegiality, reciprocity, deferral to an expert's authority and to a discipline's sovereignty, and cognitive contextualization (using another discipline's criteria of excellence when evaluating a proposal from that discipline) as key variables in the consensus-attaining process.

Beyond its theoretical value, How Professors Think should be of interest to policy-makers and scholars in Europe, as they struggle to reform the higher education system and make it fit for the twenty-first century. Lamont, a transnational scholar par excellence, knows very well both the European and North-American academic systems, and directly tackles this issue in the last chapter. The remainder of my contribution to this symposium provides an informed but by no means systematic impression of contrasts between the U.S., Spanish, and European systems of evaluation and of prospects for the reproduction of the U.S. evaluative culture in the European Union context.

My experience in the Spanish system rests on having sat in committees set up to promote scholars in the humanities and social sciences, in sociology/political science editorial boards, in sociology/political science research grant committees, in social science book award committees, and in sociology hiring committees. In the last twenty years, the Spanish evaluative culture in the social sciences has begun to change toward the U.S. model, and so have the social sciences in general and their institutional carriers. The potential for conflict in evaluation situations has thus increased considerably and led to a certain bifurcation of evaluative processes, as organizations naturally 
or intentionally shape committees to be more or less homogenous in their evaluative criteria.

In Spain the "traditional" evaluative culture did not put research "excellence" at the apex of the hierarchy of factors determining academic rewards. Distributional equality, affirmative action based on social class, seniority, the evaluated scholars' pecuniary needs, personal loyalties, political affinity, to name just a few relevant factors, often superseded the quality of research as overt legitimate criteria in most evaluative contexts, including the granting of research and related awards. When research excellence entered the picture, the dominant criteria were social and policy significance and, secondarily, broad alignment with particular theoretical paradigms (e.g. Marxism, Post-Modernism, Feminism). Recent changes in the social sciences evaluative culture reflect the gradual penetration of a positivistic epistemological style, first in Economics and Psychology, and next in other fields. This penetration runs parallel to a greater preference for explanation over description and for quantitative over qualitative methods. However, except in Economics and among a small but growing group of social scientists that has taken economic theory as their model, this positivistic turn has not translated into a commensurate emphasis in theoretical originality and relevance and in originality in topic/ question. While evaluators increasingly reward the testing of hypothesis and pay close attention to the degree of statistical refinement, much less attention is paid to the broad theoretical and substantive significance of a given piece of research. This reluctance to engage with theory and substance-in the positivistic, not in the affiliation sense-is extensive to other fields of academic evaluation, where standardized indices of quality (e.g. number of peer-reviewed publications, citation counts, publication in JCR journals), instead of careful reading of published material, are extensively relied upon.

I can only speculate about the explanatory factors underlying Spain's evaluative culture and its recent transformation. Familism, low generalized trust, the dependence of scholarly communities on the state for resources (e.g. research contracts with which they supplement their low salaries), egalitarian ideology, and latent anti-positivism may be relevant to the explanation of Spain's traditional evaluative culture. Meanwhile, economic development, the internationalization of the economy, and Spain's insertion in the European space of research and education may in turn explain some of the recent changes in this culture.

My considerable exposure to other European evaluative cultures, especially the German one, has convinced me that Spain is actually not very different from the rest of Europe and that, just like Spain, many European countries are moving closer to the U.S. system but not quite converging. Spain may simply be an extreme case of a European propensity among the social sciences to separate theoretical reflection from empirical research and to treat valid and detailed description and social and policy significance as the main criteria of excellence. Meanwhile, the positivistic turn and the simultaneous trend toward trusting indices of quality more than peer review and inter-subjective processes 
of evaluation of a person's work I observe in Spain can also be observed in other European countries.

In view of these trends one may ask whether a convergence of the U.S. and European cultures of evaluation is in sight. As with most questions related to isomorphic processes connected to globalization, the answer may be "yes, but". Convergence is already taking place, as I discuss above, but I do not see European academics prioritizing theoretical and substantive depth, relevance, and originality in the evaluation of research proposals as U.S. academics do. It is this interest in theory and substance that in fact underlies the passion, intellectual excitement, collegiality, and reliance on rational argumentation that surrounds the discussions that Lamont so vividly describes. What Lamont may have missed in her account is that this is actually the stuff of academic life in the United States. University professors spend their time with each other, in seminars, departmental meetings, conferences, social gatherings and also late at night on the telephone discussing substance and theory (and gossip too!). In this context, they learn the diplomatic skills that they then display in collective evaluation endeavors. Contrast this with the sharper boundaries that contemporary European academics draw between their work and their private life, a "9 am to $5 \mathrm{pm}$ " bourgeois mindset that strikes me as so prevalent in European academia. The U.S. peculiarity may in fact result from the relative insulation of North American universities from the rest of society-itself a consequence of the high degree of geographical mobility that characterizes the U.S. labor market and the relative financial and administrative autonomy of universities from the state.

Another factor that can help explain the greater role of theory and substance as evaluative criteria in the United States than in Europe is the more structured character of doctoral programs in the former. Although Lamont rightly stresses the potential obstacles to communication among peers in national evaluation contexts that result from the great size and diversity of the U.S. university system, this greater structure facilitates cross-national conversations to a degree rarely found in Europe. In particular, comprehensive exams or papers in one or several fields as part of these programs (aimed at ensuring that future scholars acquire command over a broad literature) contribute to create relatively homogeneous imagined communities of readers. Hence, when participating in evaluative situations, regardless of geographical and institutional location, the members of such imagined communities can interact with each other in a relatively fluent fashion. The combination of highly homogeneous imagined communities of readers with the relatively high insulation from society of U.S. universities also facilitates transdisciplinary flows of information that cannot but facilitate interaction in evaluation contexts and conversations about theory and substance.

Scholarly communication about theory and substance will remain limited and problematic, since it is unlikely that in the near future European universities will insulate themselves from society to the extent they do in the United States, and since the European Space of Higher Education is promoting short 
and unstructured doctorate programs and also the institutional separation of the M.A. and PhD. stages. Thus, it will continue to be easier for scholars in the social sciences and humanities to reach consensus and rank research proposals, based on their social and policy significance or their methodological rigor. The field of Economics will probably remain the only exception, due to the great level of theoretical consensus it has achieved.

Given how unlikely it is that national academic evaluative cultures in Europe will converge with that of the United States, prospects for a European Union evaluative culture identical to the one in the United States are even slimmer. Internal and cross-discipline contrasts in epistemological style at the national level get compounded at the European Union level because of the traditional insulation of national academic systems from each other. Deference to authority in European Union level evaluation processes in the social sciences and humanities becomes more difficult when one has no idea about who other panelists are and what processes have led them to become "authorities" in their respective countries. The same happens when it comes to deference to another discipline's sovereignty, another of the consensus-shaping mechanisms that Lamont describes. How can one defer to a discipline's sovereignty when disciplines themselves are split into different national cultures and when one is aware of the diversity of approaches to a given discipline across countries? The link between the degree of consensus in a discipline and panelists' willingness to defer to that discipline's sovereignty is in fact an issue that Lamont leaves relatively unexamined. While she synthesizes the state of each of the disciplines represented in her book, distinguishing for instance between highly unified fields (i.e. Economics and History) and divided fields (i.e. English and to a lesser extent Political Science) (chapter 3), she does not proceed to examine how these contrasts impact on the authority of different disciplines (chapter 4). I suspect that the more unified a discipline is, the greater its authority. Because of this, the problems of achieving evaluative consensus in national evaluative processes get compounded when one moves to the European Union academic field, even in evaluative panels that focus only on single disciplines.

Recent demands that the recently created European Research Council (ERC) adapts its evaluation procedures to increase the chances of funding for projects from underrepresented countries hints at the potential conflict inherent in such a diverse academic landscape like that of the European Union. Lamont's book provides useful clues about how to include diversity considerations in European Union level evaluative processes, for sensitiveness to gender and ethnic diversity enters in funding decisions in the United States without necessarily compromising the fairness of the system, as the author strongly emphasizes. I am optimistic in this respect. I am less optimistic, however, about the extent to which great intellectual diversity in the European Union may not strengthen the tendency already observable at national levels toward sacrificing theoretical and substantive relevance and originality in order to reach consensus in European Union competitions. I also fear that clarity and elegance (other 
criteria of excellence emphasized in the United States) may become victims of diversity in European Union research contests. This is because most applicants are not native speakers of English, the official language, which puts pressure on evaluative committees to be lenient on style when ranking competing research projects. In the end, methods and social and policy relevance seem to be bound to reign more sovereign in these competitions than at the national level. This would be a pity and a reason to keep on searching for inspiration in the U.S. academic culture that Lamont so nicely examines. 